\title{
Relato das atividades e dificuldades do Coletivo Mirtha Lina em meio à pandemia de Covid-19
}

\author{
Camila Sass $^{1}$, Beatriz Chicaroni ${ }^{1}$, Lara Tenore ${ }^{1}$, Lidia Ferreira ${ }^{1}$, Maria Eduarda \\ Brandão $^{1}$, Melissa Lins ${ }^{1}$, Poliana Ferreira1 ${ }^{1}$, Rosimeire Santana ${ }^{1}$, Carla Rodriguez ${ }^{2}$, \\ Denise Goya ${ }^{2}$, Rafaela V. Rocha ${ }^{2}$ \\ ${ }^{1}$ Universidade Federal do ABC (UFABC) \\ ${ }^{2}$ Centro de Matemática, Computação e Cognição (CMCC) \\ Campus Santo André - Avenida dos Estados, 5001 - Bairro Santa Terezinha \\ Santo André - SP - Brasil - CEP: 09210-580 \\ camilasass4@gmail.com, \{beatriz.chicaroni, lara.tenore, \\ lidia.trifanoff, maria.brandao, \\ melissa.lins, rosimeire.s\}@aluno.ufabc.edu.br, \{c.rodriguez, \\ denise.goya, poliana.ferreira, rafaela.rocha\}@ufabc.edu.br
}

\begin{abstract}
Currently, the proportion of women graduated or enrolled in STEM-related fields is low in most countries. This situation is worrying because it shows that women are not participating equally in one of the great pillars of our society. In view of this, this article reports the difficulties and actions of the collective of undergraduates, in the midst of the Covid-19 pandemic, to increase the participation of girls and women in these areas. Among the actions are the reformulation of the group's visual identity; training of new monitors; review of course materials; and organizing and participating in an online workshop.
\end{abstract}

Resumo. Atualmente, a proporção de mulheres graduadas ou matriculadas nas áreas relacionadas à STEM é baixa na maior parte dos países. Essa situação é preocupante pois mostra que as mulheres não estão participando de forma igualitária de um dos grandes pilares da nossa sociedade. Visto isso, este artigo relata as dificuldades e ações do coletivo de graduandas, em meio $\grave{a}$ pandemia de Covid-19, para aumentar a participacão de meninas $e$ mulheres nessas áreas. Dentre as ações, estão a reformulação da identidade visual do grupo; formação de novas monitoras; revisão de materiais dos cursos; e a organização e participação em um workshop on-line.

\section{Introdução}

Os Objetivos de Desenvolvimento Sustentável (ODS) 4 e 5 da Agenda 2030 da ONU dizem respeito à educação inclusiva e igualdade de gênero. Entretanto, essa realidade ainda está distante em áreas de STEM (Science, Technology, Engineering and Mathematics). A porcentagem de mulheres entre graduadas(os) nesses cursos é inferior a $15 \%$ em mais de dois terços dos países, e somente $25 \%$ das pessoas matriculadas em programas de engenharia, manufatura, construção e TI eram mulheres em metade dos países, segundo dados de 2016-18 [UNESCO 2020].

Esses dados são preocupantes, pois as carreiras relacionadas à STEM impactam diretamente a sociedade em diversos setores econômicos, como saúde, agricultura e indústria [Magalhães e Vendramini, 2018]. Além disso, a tecnologia também molda a maneira como as pessoas se veem e se relacionam [Amaral 2016]. Nesse sentido, é ainda mais importante ter uma melhor distribuição de gênero nessas áreas para que as 
mulheres assumam mais posições como produtoras das transformações e tecnologias que temos visto no mundo, e sejam reconhecidas pelos seus trabalhos.

O Coletivo Mirtha Lina ${ }^{1}$ visa fomentar a entrada e permanência de meninas e mulheres em cursos de graduação em STEM na Universidade Federal do ABC (UFABC). Este artigo apresenta as ações do coletivo no ano de 2020 e as dificuldades enfrentadas para dar continuidade aos cursos de capacitação [Sass et al. 2018], dado o contexto pandêmico. A interrupção dos cursos aconteceu, principalmente, pelo fato das atividades acadêmicas presenciais terem sido suspensas (Portaria $n^{\circ} 394 / 2020^{2}$ ), e o coletivo entender que parte considerável do público atendido não tem acesso a um computador com boa conexão de internet em casa.

Este artigo está estruturado em: introdução e trabalhos relacionados (Seção 1); cenário e contextualização do coletivo (Seção 2); atividades desenvolvidas neste ano atípico (Seção 3); seguidas das considerações finais, na Seção 4, com o novo planejamento, que está sendo executado e espera-se que renda bons resultados em 2021.

\section{Cenário e Contextualização}

Ribeiro et al. (2020) apontam fatores pessoais e comportamentais como os mais decisivos na escolha de alunas, de um curso técnico em Informática, pela área da computação. Com base nos resultados, sugere-se que promover ações que relacionam as atividades propostas aos interesses das estudantes e iniciativas que promovam a autoconfiança e autoeficácia podem aproximá-las mais da área [Ribeiro et al. 2020]. Andrade et al. (2020) apresentaram êxito na realização de oficinas de caráter motivacional e informativo, com alunas da UFC e com escolas da região, que fomentaram o senso de pertencimento e resultaram em interesse preliminar de algumas meninas em seguir na área. Além disso, o projeto Minerv@sDigitais, que objetiva diminuir o afastamento de mulheres da computação na UFRJ, realizou diversas ações com as alunas e destacou o potencial transformador do projeto [Galeno et al. 2020].

As ações anteriores do coletivo também obtiveram sucesso com a realização de um curso de lógica de programação para graduandas e alunas do Ensino Médio [Sass et al. 2018 e 2019]. As autoras adaptaram o conteúdo à realidade das alunas com objetivo de mostrar a presença da lógica no dia a dia delas. Os resultados indicam que a abordagem do curso, realizado na UFABC, conseguiu apresentar a carreira em computação como possibilidade à maior parte das estudantes [Sass et al. 2018 e 2019].

Entretanto, entre fevereiro e março de 2020, a realidade vivida até então mudou completamente por conta da pandemia de Covid-19. As universidades brasileiras foram impactadas e deixaram de funcionar presencialmente, algumas passaram a utilizar o formato de ensino a distância, remoto ou on-line. O cenário para nossa equipe era ainda mais delicado, por causa do luto pela perda da idealizadora do grupo, professora Mirtha Lina Fernández Venero, que faleceu no final de 2019, e da necessidade de entender quais seriam os próximos passos para fazer juz a tudo que ela havia almejado.

\footnotetext{
${ }^{1} \underline{\text { lirte.pesquisa.ufabc.edu.br/coletivo mina/\#ht-about-us-section }}$

2 ufabc.edu.br/images/stories/comunicare/boletimdeservico/boletim servico ufabc 927.pdf\#page $=6$
} 
Artigos como este, que relatam as dificuldades e a maneira encontrada de superá-las, são importantes por destacarem a necessidade da resiliência e perseverança em todo projeto e auxiliam outras iniciativas a lidarem com situações similares.

\section{Relato das Atividades Desenvolvidas}

Passado o período de adaptação, as atividades do grupo foram retomadas aos poucos. Uma das primeiras foi o estudo sobre a identidade visual do projeto e, em paralelo, foi decidido pausar os cursos de introdução à lógica de programação, pela impossibilidade de uso dos laboratórios da Universidade, e revisar todos os materiais dos cursos, além de capacitar novas alunas para ministrarem e serem monitoras em turmas futuras. Para que essas ações funcionassem à distância, foram utilizadas ferramentas como Slack e Trello, que facilitam a organização e o trabalho em equipe. Também deu-se continuidade ao trabalho nas redes sociais (Instagram e Facebook). Ainda no ano de 2020, foi realizado um evento on-line em conjunto com a equipe do projeto de extensão Diversão Séria.

\subsection{Novo Nome e Nova Identidade Visual}

Após o falecimento da professora Mirtha, as integrantes do coletivo decidiram mudar a identidade visual para homenageá-la. Para tal, foram estudados e alterados o logotipo e o nome do projeto. Deu-se início a um novo ciclo, o $++\mathrm{C} \& \mathrm{TpM}^{3}$ se transformou em Coletivo Mirtha Lina, cuja forma contraída é cMiN@.

O desenvolvimento da nova identidade visual foi dividido em quatro fases, realizadas durante o primeiro semestre de 2020: (1) Briefing: documento que consolida todas as características e objetivos de um projeto (público-alvo, objetivo, palavras-chave, frases etc.); (2) Brainstorming: painel que contém vários projetos que possuem objetivo e características semelhantes, com o intuito de comparar os elementos visuais, como logotipo, tipografia e paleta de cores; (3) Conceito do logo: no qual foram desenvolvidos rascunhos com base em uma foto de perfil da professora e nas principais ideias identificadas e sugeridas durante os passos anteriores; (4) Vetorização do conceito do logo: aplicação de ideias e cores de forma digital.

\subsection{Revisão de Materiais}

Em 2019, foram ministrados dois cursos de Introdução à lógica de programação, com as linguagens Python e JavaScript, oferecidos para meninas de escolas públicas da região do $\mathrm{ABC}$ e para ingressantes da UFABC. Logo nessa primeira turma de JavaScript, percebeu-se que seu conteúdo estava bastante denso para a compreensão das alunas, pois além de introduzir a lógica de programação com JavaScript, apresentava conteúdos básicos sobre HTML e CSS para tornar a apresentação de resultados mais lúdica.

Em 2020, após algumas discussões, foi decidido que os ensinamentos sobre HTML e CSS seriam mantidos, por terem despertado bastante interesse nas alunas. Foi feita então uma reformulação do material, com atualização de tópicos e uso de novas ferramentas que o tornam mais didático, além do acréscimo de uma aula na carga horária do curso, o qual passou a ter 18 horas (divididas em seis encontros de três horas). O material do curso de Python também foi revisado e atualizado com alguns

\footnotetext{
${ }^{3}$ Desmistificando a Ciência da Computação e as Tecnologias da Informação por e para Mulheres
} 
ajustes referentes à apresentação de certos tópicos, como declaração de variáveis, estruturas condicionais e de repetição. As mudanças foram realizadas a fim de apresentar a lógica de programação de forma ainda mais aplicável ao cotidiano das alunas, bem como facilitar o suporte das novas monitoras às alunas durante o curso, por meio de exemplos simples para cada tópico. Além disso, novos exercícios foram criados ou adaptados, considerando os diferentes níveis de dificuldade.

\subsection{Capacitação das Monitoras}

Em 2019, o curso de Python obteve 126 inscrições e o de JavaScript, 70. Devido à limitação de monitoras disponíveis e capacitadas para ministrar as aulas, foram oferecidas somente 30 vagas para cada curso. Em 2020, novas monitoras foram capacitadas com objetivo de ofertar mais vagas nas próximas turmas. Para isso, foram realizadas aulas semanais de 50 minutos, com duas ministrantes e três monitoras para o curso de JS em cinco encontros; e uma ministrante e cinco monitoras do curso de Python em quatro encontros. Em cada treinamento, seguiu-se o material atualizado, que será utilizado em turmas futuras, com foco no compartilhamento de conhecimentos técnicos e voltados às estratégias de ensino e organização durante as aulas.

Ao final, os materiais foram aprovados pelas participantes, considerando a didática ao longo do treinamento, a quantidade de conteúdo e exercícios propostos para cada aula, a clareza com a qual os conteúdos são apresentados, como também se elas se sentiam capazes de auxiliar as turmas como ministrantes e/ou monitoras.

\subsection{Organização de Workshop On-line}

Entre os dias 19 e 23 de outubro de 2020, foi realizado o II Workshop Diversão Séria e Dias da Ada, de forma inteiramente virtual, nas plataformas Discord e Youtube. A organização foi feita em conjunto com alunas(os) e professoras do projeto Diversão Séria. Todas as atividades promovidas foram gratuitas e abertas ao público. Na programação, havia cinco rodas de conversa, três palestras, três mesas-redondas, 13 apresentações de trabalhos e seis partidas de jogos on-line para integração das(os) participantes, resultando em 26,5 horas de atividades. O workshop teve 199 inscritas(os) e 103 participantes em alguma das atividades (51,75\% de presença, 57,28\% de mulheres), com média de 4,5 e mediana de 3 atividades por participante.

As alunas do coletivo promoveram uma roda de conversa com dicas para ingressantes na Universidade (com 29 participantes, 55,17\% mulheres) e também participaram de duas mesas redondas: (1) uma sobre mulheres nas exatas, na qual falaram sobre mulheres na matemática na Idade Moderna e de um podcast sobre mulheres na computação (com 34 participantes, 66,70\% mulheres); e (2) outra mesa sobre grupos de mulheres nas exatas, que proporcionou a interação com uma professora integrante de um grupo de mulheres na tecnologia da Universidade Federal da Paraíba (UFPB) (22 participantes, 81,82\% mulheres).

O evento foi uma oportunidade de aproximar o grupo da comunidade e também proporcionou momentos de aprendizado às participantes do projeto, por meio da troca de experiências com outros grupos de mulheres nas exatas. 


\section{Conclusões e Trabalhos Futuros}

Neste artigo, foram apresentadas as principais atividades desenvolvidas pelo Coletivo Mirtha Lina ao longo de um ano atípico, em que foi preciso enfrentar as dificuldades; olhar e entender questões internas; repaginar os canais de comunicação externa; reformular materiais levados para a comunidade; se comunicar nas redes sociais considerando o cenário de vulnerabilidade das pessoas; e fomentar outros projetos que também trabalham para o aumento de mulheres nas áreas de STEM.

Este relato foi feito com o intuito de incentivar outros grupos com interesses similares, que também enfrentaram tais dificuldades em 2020, a seguir em busca de seus objetivos. Com resiliência e criatividade é possível impactar a vida de meninas e mulheres, que muitas vezes nem cogitariam as carreiras de STEM como uma possibilidade, caso não entrassem em contato com projetos como este.

Em 2021, o coletivo se expande por meio de dois projetos de extensão aprovados pela UFABC. O MirTic@, projeto de letramento e inclusão digital para crianças e adolescentes em situação de vulnerabilidade em instituições de abrigamento. E o UFABC para MiN@s, que visa aproximar meninas do final do Ensino Fundamental II e início do Ensino Médio das áreas STEM. Com estes dois projetos, o coletivo amplia seu público-alvo e passa a fomentar a entrada e permanência de meninas e mulheres não somente na Ciência da Computação, mas nas áreas relacionadas à STEM principalmente nas que ainda possuem um baixo percentual de presença feminina.

\section{Referências}

Amaral, R. D. (2016). Exposição privada nas redes sociais: uma análise sobre o Facebook na sociedade contemporânea. Tese (Doutorado). UNESP, FCT.

Andrade, L. M. M. D. S. et al. (2020). Ações Iniciais do Projeto de Extensão Garotas Tech dos Sertões de Crateús para Captação e Retenção de Meninas aos Cursos de TI da UFC-Crateús. In WIT pages 169-173. SBC.

Galeno, L. M. D. F. et al. (2020). Minerv@s Digitais: encorajando e acolhendo mulheres na computação. In WIT pages 70-79. SBC.

Magalhães, R. and Vendramini, A. (2018). Os impactos da quarta Revolução Industrial. GV-Executivo, 17(1):40-43.

Ribeiro, K.S.F.M. and Maciel, C. (2020) Fatores de Influência na Escolha pela Continuidade da Carreira em Computação pelas Estudantes de Ensino Médio Técnico em Informática. In WIT pages 40-49.

Sass, C. et al. (2018). Um relato sobre estratégias de motivação e ensino de lógica de programação para e por mulheres. In CBIE pages 659-668. SBC.

Sass, C. et al. (2019). A report on strategies for motivating and developing the computational thinking for and by women. JCThink, 3(1):34-49.

UNESCO. (2020). Relatório de Monitoramento Global da Educação 2020: Uma nova geração: 25 anos de esforços pela igualdade de gênero na educação. https://unesdoc.unesco.org/ark:/48223/pf0000375599/PDF/375599por.pdf.multi. Acessado em: 07/03/2021. 